\title{
Cannabis Use Is Quantitatively Associated with Nucleus Accumbens and Amygdala Abnormalities in Young Adult Recreational Users
}

\author{
Jodi M. Gilman, ${ }^{1,4,5}$ John K. Kuster, ${ }^{1,2 \star}$ Sang Lee, ${ }^{1,6 *}$ Myung Joo Lee, ${ }^{1,6 *}$ Byoung Woo Kim, ${ }^{1,6}$ Nikos Makris, ${ }^{3,5}$ \\ Andre van der Kouwe, ${ }^{4,5}$ Anne J. Blood, ${ }^{1,2,4,5} \uparrow$ and Hans C. Breiter ${ }^{1,2,4,6} \dagger$ \\ ${ }^{1}$ Laboratory of Neuroimaging and Genetics, Department of Psychiatry, ${ }^{2}$ Mood and Motor Control Laboratory, ${ }^{3}$ Center for Morphometric Analysis, \\ Department of Psychiatry, and ${ }^{4}$ Athinoula A. Martinos Center in Biomedical Imaging, Department of Radiology, Massachusetts General Hospital, \\ Charlestown, Massachusetts 02129, ${ }^{5} \mathrm{Harvard}$ Medical School, Boston, Massachusetts 02115, and ${ }^{\circ}$ Warren Wright Adolescent Center, Department of \\ Psychiatry and Behavioral Sciences, Northwestern University Feinberg School of Medicine, Chicago, Illinois 06011
}

\begin{abstract}
Marijuana is the most commonly used illicit drug in the United States, but little is known about its effects on the human brain, particularly on reward/aversion regions implicated in addiction, such as the nucleus accumbens and amygdala. Animal studies show structural changes in brain regions such as the nucleus accumbens after exposure to $\Delta$-tetrahydrocannabinol, but less is known about cannabis use and brain morphometry in these regions in humans. We collected high-resolution MRI scans on young adult recreational marijuana users and nonusing controls and conducted three independent analyses of morphometry in these structures: (1) gray matter density using voxel-based morphometry, (2) volume (total brain and regional volumes), and (3) shape (surface morphometry). Gray matter density analyses revealed greater gray matter density in marijuana users than in control participants in the left nucleus accumbens extending to subcallosal cortex, hypothalamus, sublenticular extended amygdala, and left amygdala, even after controlling for age, sex, alcohol use, and cigarette smoking. Trend-level effects were observed for a volume increase in the left nucleus accumbens only. Significant shape differences were detected in the left nucleus accumbens and right amygdala. The left nucleus accumbens showed salient exposuredependent alterations across all three measures and an altered multimodal relationship across measures in the marijuana group. These data suggest that marijuana exposure, even in young recreational users, is associated with exposure-dependent alterations of the neural matrix of core reward structures and is consistent with animal studies of changes in dendritic arborization.
\end{abstract}

Key words: cannabis; gray matter density; marijuana; multimodal imaging; reward; topology/shape

\section{Introduction}

Marijuana (cannabis) is the most commonly used illicit drug in the United States (15.2 million past-month users; US Department of Health and Human Services, 2008). It is also the most widely used illicit drug on college campuses (Mohler-Kuo et al., 2003). Moreover, its use is increasing among adolescents and

Received Nov. 6, 2013; revised March 9, 2014; accepted March 11, 2014.

Author contributions: J.M.G., M.J.L., B.K., N.M., A.J.v.d.K., A.B., and H.C.B. designed research; J.M.G., J.K.K., S.L., and A.J.v.d.K. performed research; M.J.L., B.K., A.B., and H.C.B. contributed unpublished reagents/analytic tools; J.M.G., J.K.K., S.L., M.J.L., N.M., A.B., and H.C.B. analyzed data; J.M.G., A.B., and H.C.B. wrote the paper.

This work was supported by the National Institute on Drug Abuse (Grants 14118,026002, 026104, and 027804 to H.C.B. and Grant 034093 to J.M.G.), the Office of National Drug Control Policy, Counterdrug Technology Assessment Center (Grants DABK39-03-0098 and DABK39-03-C-0098), and the National Institute of Neurological Disorders and Stroke, National Institutes of Health (Grant 052368 to A.J.B.). H.C.B. was also supported by the Warren Wright Adolescent Center at Northwestern Memorial Hospital and Northwestern University, Chicago. J.M.G. was supported by a Harvard Medical School Norman E. Zinberg Fellowship in Addiction Psychiatry Research.

The authors declare no competing financial interests.

*J.K.K., S.L., and M.J.L. contributed equally to this work.

†A.J.B. and H.C.B. contributed equally to this work.

Correspondence should be addressed to Hans Breiter, MD, Warren Wright Adolescent Center, Department of Psychiatry and Behavioral Sciences, Northwestern University Feinberg School of Medicine, 710 N. Lake Shore Dr., Abbott Hall 1301, Chicago, IL 60611. E-mail: h-breiter@northwestern.edu.

DOI:10.1523/JNEUROSCI.4745-13.2014

Copyright $\odot 2014$ the authors $\quad 0270-6474 / 14 / 345529-10 \$ 15.00 / 0$ young adults (Henry et al., 2003), partially due to society's changing beliefs about cannabis use and its legal status.

Cannabis use is associated with impairments of cognitive functions, including learning and memory, attention, and decision-making. Animal studies show structural changes in brain regions underlying these functions after exposure to $\Delta 9$ tetrahydrocannabinol (THC), the main psychoactive component of cannabis (Lawston et al., 2000; Downer et al., 2001). In the nucleus accumbens, the length of the dendrites and number of dendritic spines increases with THC exposure in rats (Kolb et al., 2006). Less is known about the relationship between cannabis use and brain structure in humans. Although some studies have shown volume reductions in the hippocampus, amygdala, and cerebellum, others have not shown such effects (see Lorenzetti et al., 2010 for review). Differences in methodology may have contributed to these mixed results, suggesting that using a variety of structural methods together to quantify brain morphology may be important.

In the present study, we collected high-resolution T1 MRI scans on young adult (age 18-25 years) cannabis/marijuana users and matched nonusing controls. We conducted three blinded, automated, and independent analyses of brain structure and their 
interaction: (1) gray matter density using voxel-based morphometry, (2) volume (regional volumes of deep gray matter structures) to investigate gross volumetric differences, and (3) shape deformation (surface topology) to investigate localized shape differences of subcortical structures. Although most previous studies have investigated the effect of cannabis use in heavy, dependent users, the present study posed the question of whether even recreational use may be associated with brain abnormalities.

Although THC acts centrally across a number of brain regions, the amygdala and the nucleus accumbens are especially likely to be affected. THC binds to endogenous cannabinoid (CB1) receptors located in brain regions including the nucleus accumbens and amygdala (Burns et al., 2007). Converging findings in the addiction literature implicate these regions as being important to the impact that marijuana may have on the brain (for review, see Koob and Volkow, 2010). First, the nucleus accumbens and amygdala have been implicated in non-drug reward processing (Blood and Zatorre, 2001; Breiter et al., 2001), as well as with the euphoria associated with the rewarding effects of drugs (Breiter et al., 1997; Gálvez-Buccollini et al., 2008; Gilman et al., 2008). Second, animal studies have demonstrated that exogenous and endogenous cannabinoids can significantly alter synaptic transmission in the nucleus accumbens (Lupica et al., 2004) and in the amygdala (Azad et al., 2004). Third, animal studies have shown that structural abnormalities can occur in the nucleus accumbens of THC-treated animals (Kolb et al., 2006). Accordingly, our hypothesis was that cannabis use would be associated with gray matter density alterations in the nucleus accumbens and the amygdala, potentially affecting volume and shape measures of these regions or relationships among these measures.

\section{Materials and Methods}

Participants. Participants in this study were 20 young adult (age 18-25 years) current marijuana users and 20 controls. Marijuana and control participants were matched on age, sex $(9$ males and 11 females in each group), handedness, race, and years of education. All participants were right-handed. Marijuana participants used marijuana at least once a week, but were not dependent, according a Structured Clinical Interview for the DSM-IV (SCID; First et al., 2002). Marijuana participants were not excluded if they had used other illegal drugs in the past; however, they were excluded if they met abuse criteria for any drug other than marijuana. Control participants had not used marijuana in the past year and had used marijuana on less than five occasions in their lifetime. Marijuana and control participants were medically healthy and did not meet DSM-IV criteria for any current or lifetime Axis I disorder. All participants completed the Alcohol Use Disorder Identification Test (AUDIT; Saunders et al., 1993) to check for problem drinking; any potential participant scoring above an 8 was excluded from inclusion in the final cohort of matched participants.

Procedure. Participants completed screening and scanning during one study visit. All marijuana users were asked to refrain from using substances on the day of the study. We performed a urine drug screen that tested for cannabis, amphetamines, cocaine, barbiturates, methamphetamines, benzodiazepines, codeine, morphine, and ethanol. Because $\mathrm{THCCOOH}$, the main secondary metabolite of THC, can be detected in urine several weeks after last use (Fraser et al., 2002), a urine test alone could not determine with certainty whether participants were acutely intoxicated. Therefore, we ensured that no participant exhibited overt signs of intoxication based on a four-item marijuana intoxication scale developed in our laboratory that was designed to assess four signs of acute intoxication (Karschner et al., 2011): increased resting heart rate ( $>100$ beats/minute), congestion of the conjunctival blood vessels (red eyes), slowed speech response, and giddiness. No marijuana participants were excluded based on these criteria. All study procedures were approved by the Massachusetts General Hospital (MGH) Institutional Re- view Board and informed consent was obtained after the nature and possible consequences of the studies were explained.

Acquisition and processing of neuroimaging data. Participants were scanned using a 3T Siemens Trio scanner with a 32-channel head coil at the Martinos Center for Biomedical Imaging. Whole-brain T1-weighted $1 \mathrm{~mm}$ isotropic structural scans were collected using a 3D multiecho MPRAGE sequence (176 sagittal slices, FOV $256 \mathrm{~mm}$, TR $2530 \mathrm{~ms}$, TI $1200 \mathrm{~ms}, 2 \times$ GRAPPA acceleration, TE 1.64/3.5/5.36/7.22 ms, BW 651 $\mathrm{Hz} / \mathrm{px}, T_{\text {acq }}$ 6:03 min; van der Kouwe et al., 2008). Functional scans were collected using a 2D gradient echo EPI sequence ( 31 slices, $3 \mathrm{~mm}$ thick, $0.6 \mathrm{~mm}$ gap, FOV $216 \mathrm{~mm}, 3 \mathrm{~mm}^{2}$ in-plane resolution, TR $2 \mathrm{~s}$, TE $30 \mathrm{~ms}$, BW $2240 \mathrm{~Hz} / \mathrm{px})$. All acquisitions were automatically positioned using AutoAlign (van der Kouwe et al., 2005). All scans were checked for movement in case any participant moved $>3 \mathrm{~mm}$ (Breiter et al., 1997; Gasic et al., 2009). No participants were excluded based on these criteria.

Voxel-based morphometry analysis. Structural data were analyzed in a blinded fashion with the standard automated processing stream of FSL-VBM (http://fsl.fmrib.ox.ac.uk/fsl/fslwiki/FSLVBM), an optimized voxel-based morphometry protocol performed with FSL tools. First, structural images were brain extracted and gray matter segmented before being registered to the $2 \mathrm{~mm}$ MNI 152 standard space using nonlinear registration (Andersson and Smith, 2007). The resulting images were averaged and flipped along the $x$-axis to create a left-right symmetric, study-specific gray matter template. Second, all native gray matter images were nonlinearly registered to this study-specific template and "modulated" to correct for local expansion (or contraction) due to the nonlinear component of the spatial transformation. The modulated gray matter images were then smoothed with an isotropic Gaussian kernel with a $\sigma$ of $3 \mathrm{~mm}(\mathrm{FWHM}=6.9 \mathrm{~mm})$. Finally, a voxelwise general linear model was applied using permutation-based nonparametric testing, correcting for multiple comparisons across space.

Clusters were identified using two concurrent criteria: (1) a significance threshold for peak $t$ values corrected for multiple comparisons using a Bonferroni correction and (2) a cluster threshold for voxels adjacent to the peak voxel, along with a minimum cluster size. The maximum voxel (max vox) threshold for each cluster was set based on the total search volume of $4920 \mathrm{~mm}^{3}$ for the bilateral nucleus accumbens and amygdalae, which, divided by a minimum target cluster of five voxels $\left(40 \mathrm{~mm}^{3}\right)$, implied a correction of $0.05 / 123=0.0004(z=3.5)$ for the max vox of putative clusters. The second threshold for cluster voxels outside of the max vox was selected on the basis of what correction would suffice for a search volume of just one of the four a priori structures. The largest of the nucleus accumbens and amygdala volumes was the left amygdala $\left(1848 \mathrm{~mm}^{3}\right)$, which, divided by a minimum cluster size of five voxels $\left(40 \mathrm{~mm}^{3}\right)$, suggested a correction of $0.05 / 46.2=0.001(z=3.3)$ as a significance level for all non-max voxels in a target cluster. These methods have been used previously (Breiter et al., 1997; Makris et al., 2008; Blood et al., 2010; Blood et al., 2012). To supply information for follow-up hypotheses by other investigators, all clusters outside of the nucleus accumbens and amygdala that met these two criteria were also tabulated in Table 3.

In addition to a cluster-based analysis, we also investigated focal voxelbased morphometry differences in morphometric segmentations of a priori regions (left and right nucleus accumbens and amygdala; Gasic et al., 2009). To investigate these segmented regions in a blinded manner, we averaged voxel-based morphometry values over a $3 \times 3 \times 3$ voxel volume (27 total voxels) around the peak within each MNI segmentation and extracted these data from each participant, randomly represented by a number from 001 to 040 . The coordinates (in millimeters) of these ROIs were based on the max vox of the difference cluster constrained by the anatomical segmentations of the nucleus accumbens and amygdala (Gasic et al., 2009) observed in the left hemisphere structures and the mirror location of these maxima in the right hemisphere. These locations were as follows: left nucleus accumbens $=-12,8,-12$; right nucleus accumbens $=12,8,-12$; left amygdala $=-24,-10,-10$; and right amygdala $=24,-10,-10$. These values were entered into a multivariate general linear model (SPSS Version 19), which allowed us to determine whether group differences were significant after covarying for factors including age, sex, alcohol use, and cigarette smoking. In addition, to 
Table 1. Participant demographics

\begin{tabular}{|c|c|c|c|}
\hline & $\operatorname{CON}(n=20)$ & $\operatorname{MJ}(n=20)$ & $p$-value \\
\hline $\operatorname{Sex}(M / F)$ & $9 \mathrm{M} / 11 \mathrm{~F}$ & $9 \mathrm{M} / 11 \mathrm{~F}$ & $\mathrm{~N} / \mathrm{A}$ \\
\hline Age & $20.7(1.9)$ & $21.3(1.9)$ & 0.30 \\
\hline Years of education & $14.3(3.4)$ & $12.6(4.8)$ & 0.20 \\
\hline \multicolumn{4}{|l|}{ STAl $^{a}$} \\
\hline State & $28.9(7.94)$ & $27.7(7.38)$ & 0.65 \\
\hline Trait & $29.8(7.32)$ & $29.5(5.56)$ & 0.89 \\
\hline HAM-D $D^{b}$ & 0.80 (1.40) [range: $0-5]$ & 1.10 (1.37) [range: $0-5]$ & 0.50 \\
\hline \multicolumn{4}{|l|}{$\mathrm{TIPI}^{\mathrm{c}}$} \\
\hline Extroversion & $10.9(2.36)$ & $10.7(2.13)$ & 0.78 \\
\hline Agreeableness & $10.8(2.47)$ & $10.7(1.81)$ & 0.94 \\
\hline Conscientiousness & $11.9(2.08)$ & $11.7(2.13)$ & 0.76 \\
\hline Emotional stability & $10.5(2.52)$ & $11.4(2.64)$ & 0.27 \\
\hline Openness & $12.1(1.90)$ & $12.4(1.61)$ & 0.57 \\
\hline \multicolumn{4}{|l|}{ Substance use } \\
\hline \multicolumn{4}{|l|}{ Alcohol } \\
\hline No. alcoholic drinks/week & $2.64(2.38)$ & $5.09(4.69)$ & 0.10 \\
\hline AUDIT score & $3.30(1.78)$ & $5.50(2.21)$ & 0.05 \\
\hline \multicolumn{4}{|l|}{ Cigarettes } \\
\hline No. of occasional smokers ${ }^{d}$ & 0 & 7 & $\mathrm{~N} / \mathrm{A}$ \\
\hline No. of daily smokers & 0 & 1 & $\mathrm{~N} / \mathrm{A}$ \\
\hline \multicolumn{4}{|l|}{ Marijuana } \\
\hline No. days/week & 0 & $3.83(2.36)$ & $\mathrm{N} / \mathrm{A}$ \\
\hline No. joints/week & 0 & $11.2(9.61)$ & $\mathrm{N} / \mathrm{A}$ \\
\hline No. joints/occasion & 0 & $1.80(0.77)$ & $\mathrm{N} / \mathrm{A}$ \\
\hline No. smoking occasions/day & 0 & $1.80(0.70)$ & $\mathrm{N} / \mathrm{A}$ \\
\hline Age of onset (years) & - & $16.6(2.13)$ & $\mathrm{N} / \mathrm{A}$ \\
\hline Duration of use (years) & - & $6.21(3.43)$ & $\mathrm{N} / \mathrm{A}$ \\
\hline
\end{tabular}

All values are expressed in means and SDs. CON, controls; MJ, marijuana users.

${ }^{a}$ State Trait Anxiety Inventory Form (Spielberger et al., 1983).

${ }^{b}$ Hamilton Depression Rating Scale (Hamilton, 1960).

'Ten-Item Personality Inventory (Gosling et al., 2003).

${ }^{d}$ Occasional smokers reported from 1 cigarette/week to 1 cigarette every 3 months.

determine whether gray matter density was associated with drug use severity, we performed linear regressions between the average values of each ROI and measures of drug use behavior including: number of joints smoked per week, smoking occasions per day, smoking days per week, and number of joints smoked per smoking occasion (see Behavioral Measures below). Because we conducted these tests in four regions (left and right nucleus accumbens and amygdala), we performed a Bonferroni correction on the resulting $p$-values $(p<0.05 / 4=0.0125)$ for the voxel-based morphometry analysis. We did not correct for the number of drug use measures because these measures tend not be independent of each other (i.e., smoking occasions per day, joints per occasion, joints per week, and smoking days per week were all highly correlated, with $p<0.01$ ).

Volume analysis. Intracranial volume (ICV), total brain, gray matter, white matter, and subcortical volumes were estimated using the standard automated cortical and subcortical segmentations created by Freesurfer (http://surfer.nmr.mgh.harvard.edu), again performed in a blinded manner. Summary images for the segmentation outputs were generated to check the quality of segmentations and these segmentations were also spot checked using a blinded approach by an expert neuroanatomist (N.M.), who directs the MGH Center for Morphometric Analysis (CMA). We extracted volumes of our a priori regions (left and right nucleus accumbens and amygdala) in each of the 40 participants. As with the gray matter density measures from described in Voxel-based morphomety analysis, above, these volume measurements were entered into a multivariate general linear model, which allowed us to determine whether group differences were significant after covarying factors such as age, sex, alcohol use, and cigarette smoking. In addition, we performed linear regressions between the volume of each region and measures of drug use behavior (see Behavioral Measures below). Because we conducted these tests in four regions (left and right nucleus accumbens and amygdala), we performed a Bonferroni correction on the resulting $p$-values $(p<0.05 / 4=0.0125)$.

We also extracted values of other striatal structures (i.e., caudate and putamen), the medial temporal regions (i.e., hippocampus) and thala- mus, to assess whether there were differences between groups in these measures that met the threshold set for a priori regions. Values for these brain volumes, along with a priori regions, are listed in Table 5. In these analyses, ICV and sex were used as covariates.

Shape analysis. Shape of subcortical structures was computed using FMRIB's Integrated Registration and Segmentation Tool (FIRST), a model-based segmentation/registration tool that segments all of the subcortical structures, producing mesh and volumetric outputs (applying boundary correction) of subcortical structures. The shape/appearance models used in FIRST were constructed from manually segmented images provided by the CMA, which were segmented in a blinded fashion. Further analyses by FIRST were also performed in a blinded fashion. The manual labels were parameterized as surface meshes and modeled as a point distribution model. Deformable surfaces were used to automatically parameterize the volumetric labels in terms of meshes; the deformable surfaces were constrained to preserve vertex correspondence across the training data. Furthermore, normalized intensities along the surface normals were sampled and modeled. The shape and appearance model was based on multivariate Gaussian assumptions. Shape was then expressed as a mean with modes of variation (principal components). More information about these analyses can be found at http://fsl.fmrib.ox. ac.uk/fsl/fslwiki/FIRST/UserGuide\#Vertex_Analysis_.28with_NEW_ features_in_v5.0.0.29.

After vertices were calculated for each ROI, each a priori region (left and right nucleus accumbens and amygdala) was compared between control and marijuana participants using FSL's "Randomise" a permutation test enabling modeling and inference using standard general linear model design setup (Nichols and Holmes, 2002). Of these, two met a cluster correction threshold for familywise error of $p<0.05$ (left nucleus accumbens and right amygdala). The right nucleus accumbens and left amygdala did not meet the cluster correction threshold for significant differences between groups. From the resulting statistical maps generated by "Randomise" we identified the peak voxel showing the maximum 
deformation between the groups for each ROI. We then extracted individual scalar values (representing shape change from the average normal surface) for all 40 participants. The data extracted from these ROIs were then entered into a general linear model, allowing us to investigate differences between groups while controlling for other factors such as age, sex, alcohol use, and cigarette smoking. In addition, we performed linear regressions between individual scalar values of maximum shape deformation and measures of drug use behavior (see Behavioral Measures below). Because we conducted these tests in four regions (left and right accumbens and amygdala), we performed a Bonferroni correction on the resulting $p$-values $(p<0.05 / 4=0.0125)$.

Multimodal data integration. For multimodal analysis of gray matter density, volume, and shape (topology) measures, we focused on assessments between marijuana users and control groups for each of the four a priori structures alone (a) and the relationship between hemispheres for the nucleus accumbens and amygdala (b). The relationship among gray matter density, volume, and shape measures was evaluated for (a) and (b) using covariance matrices with SPSS Version 19 software and tabulated as bivariate correlations in Tables 6 and 7. The data used as input to these matrices included the following: (1) extracted ROIbased gray matter density data per participant, (2) volumes per participant, and (3) scalar values (representing shape change from the average normal surface) for participants from the peak voxel showing the maximum deformation between the groups. For analyses of (a) and (b), differences of $r>0.4$ between matrix elements from each group were further evaluated graphically (see Fig. 2C) and assessed to determine whether significant effects found in one group were absent in the other. These techniques were developed by the concerted effort of M.J.L., A.J.B., and H.C.B. and were then used in this study as a first application.

Behavioral measures. Marijuana users completed a timeline follow-back (Sobell et al., 1986) asking them to indicate, for the past $90 \mathrm{~d}$, the days that they smoked marijuana. They were given a calendar and asked to check off to the best of their ability the days that they smoked marijuana, focusing on patterns of use. They were also asked to designate, on the days that they used marijuana, how many separate times in a day they used and how many joints (or joint equivalents) they consumed per smoking occasion. All participants (marijuana users and controls) also completed a timeline follow-back for alcohol use, (Sobell et al., 1986) asking them to detail their drinking behavior in the past $90 \mathrm{~d}$ to determine whether alcohol consumption differed and to use as a covariate in contrasts between the two groups. All participants also completed the State Trait Anxiety Inventory Form (STAI; Spielberger et al., $1983)$ to assess anxiety, the Hamilton Depression Rating Scale (HAM-D; Hamilton, 1960) to assess depression, and the Ten-Item Personality Inventory (TIPI; Gosling et al., 2003) to assess personality characteristics.

\section{Results}

\section{Participants}

Control and marijuana participants were not significantly different in age, sex, years of education, handedness, or race; they also did not differ significantly on any of the behavioral questionnaires (STAI,
A Gray Matter Density: Marijuana > Control Participants

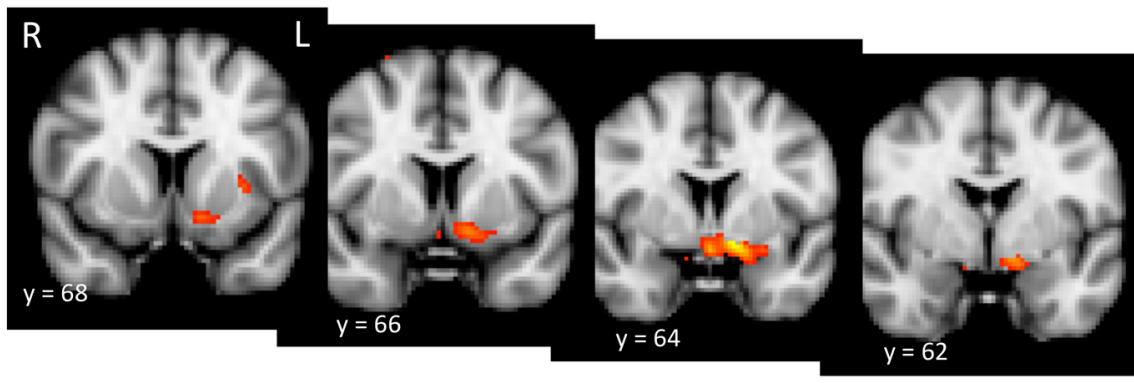

B Associations Drug Use Behavior and Gray Matter Density in Left Nucleus Accumbens
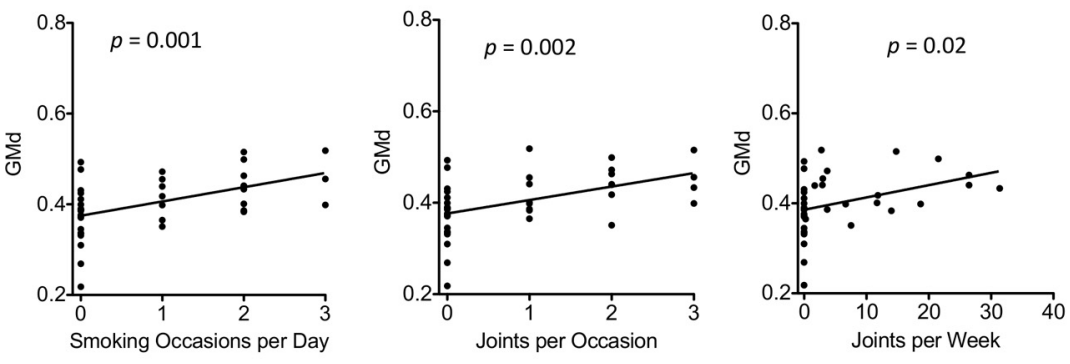

Figure 1. A, Whole-brain voxel-based morphometry between marijuana users and control participants. Images are thresholded at $z=2.5$. The most significant increases in gray matter density were in the left nucleus accumbens extending to the hypothalamus, sublenticular extended amygdala, and amygdala (Tables 2 and 3). B, Associations between gray matter density and density. $C$, Nucleus accumbens volume was increased in marijuana users and was associated with drug use measures. Error bars represent SE. An asterisk above the bar chart on left indicates that significance met $p<0.05$ uncorrected ( $p=0.037$; Table 2) which was a trend effect after correcting multiple comparisons. The association with drug use, after correcting for 4 comparisons ( $p=0.05 / 4$, or 0.0125 ), was determined to be a trend toward significance (Table 4). CON, Controls; MJ, marijuana participants.

HAM-D, and TIPI; all $p>0.05$; Table 1). Marijuana users reported drinking a greater number of alcoholic drinks per week than control participants and showed a trend toward a significant difference on AUDIT (Table 1), so alcohol use was used as a covariate in statistical analyses (see Table 2 footnotes).

\section{Gray matter density measures}

The whole-brain gray matter density analysis revealed greater density values in marijuana users than in control participants in the left nucleus accumbens, extending to subcallosal cortex, hypothalamus, sublenticular extended amygdala, and left amygdala (Fig. 1A, Tables 2, 3). When we extracted data from each participant using peak ROI values, these differences remained significant after controlling for age, sex, alcohol use, and cigarette smoking (Table 2). Gray matter density in the left nucleus accumbens and the left amygdala was further associated significantly with marijuana drug use behaviors (Fig. 1B, Table 4), but not with age of onset of marijuana use, potentially due to the tight range of onset in this cohort. 
Table 2. Structural measures of marijuana users (MJ) and controls (CON) in the amygdala and nucleus accumbens

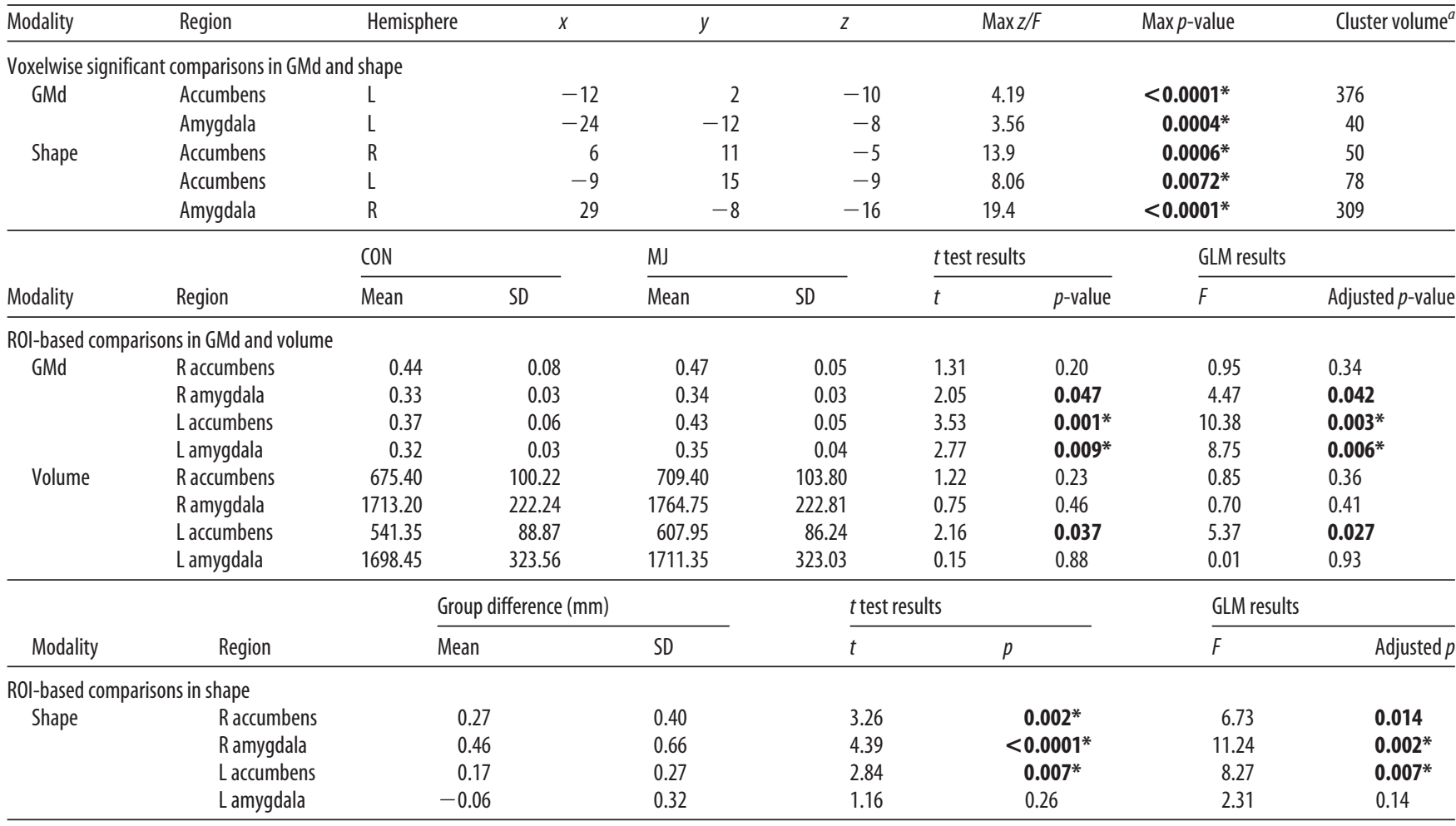

Coordinates are in MNI space and are listed in millimeters. Reported $p$ values are uncorrected; please see Materials and Methods for whole-brain correction. Gray matter density (GMd) measures reflect ROI average density. Volume is indicated in cubic millimeters. Shape values were obtained by identifying the voxel showing the peak differences between groups within each ROl and extracting the value of that peak voxel in each individual subject. The mean difference between relative group averages is shown in millimeters. For measures, group differences between the 20 controls and $20 \mathrm{MJs}$ are reported as $t$ statistics. Individual subject values were covaried in a general linear model (GLM) to account for age, sex, alcohol use, and cigarette smoking, yielding $F$ and adjusted $p$ values. Values at $p<0.05$ uncorrected are shown in bold; an asterisk indicates that these values met correction for multiple comparisons (e.g., $p<0.0125$ ).

${ }^{a} \mathrm{GMd}$ difference cluster volume is shown in cubic millimeters and shape difference cluster volume in square millimeters.

Table 3. Significant differences in gray matter density between marijuana users (MJ) and healthy controls (CON): whole-brain analysis

\begin{tabular}{|c|c|c|c|c|c|c|c|}
\hline Area & Region & Hemisphere & $x$ & $y$ & $z$ & Peak z & Volume, $\mathrm{mm}^{3}$ \\
\hline \multicolumn{8}{|l|}{$\mathrm{MJ}>\mathrm{CON}$} \\
\hline Frontal & Middle frontal gyrus & $\mathrm{R}$ & 30 & -10 & 44 & 3.71 & 48 \\
\hline \multirow[t]{2}{*}{ Parietal } & Precuneus & $\mathrm{R}$ & 24 & -60 & 26 & 4.16 & 472 \\
\hline & Postcentral gyrus & L & -24 & -36 & 58 & 3.75 & 184 \\
\hline Temporal & Insula & L & -30 & 14 & 2 & 3.63 & 80 \\
\hline \multirow[t]{2}{*}{ Subcortical } & Nucleus accumbens/putamen & L & -12 & 2 & -10 & 4.19 & 296 \\
\hline & Amygdala & L & -24 & -12 & -8 & 3.56 & 40 \\
\hline \multirow[t]{2}{*}{ Occipital } & Lateral occipital cortex & $\mathrm{R}$ & 36 & -76 & 30 & 3.69 & 48 \\
\hline & Occipital cortex & $\mathrm{L}$ & -20 & -78 & 26 & 3.73 & 56 \\
\hline \multicolumn{8}{|l|}{$\mathrm{CON}>\mathrm{MJ}$} \\
\hline \multirow[t]{4}{*}{ Frontal } & Frontal pole & $\mathrm{R}$ & 32 & 54 & 6 & 3.94 & 760 \\
\hline & Dorsolateral prefrontal cortex & $\mathrm{R}$ & 36 & -16 & 48 & 3.94 & 448 \\
\hline & Middle frontal gyrus & $\mathrm{R}$ & 30 & 20 & 58 & 3.67 & 80 \\
\hline & Frontal pole & L & -20 & 68 & -6 & 4.62 & 40 \\
\hline \multirow[t]{2}{*}{ Temporal } & Temporal pole & L & -32 & 8 & -48 & 4.42 & 312 \\
\hline & Superior temporal gyrus & L & -48 & -6 & -12 & 3.60 & 88 \\
\hline Occipital & Lateral occipital cortex & $\mathrm{R}$ & 8 & -66 & 66 & 3.77 & 72 \\
\hline
\end{tabular}

All clusters were derived from a VBM analysis. Significant clusters consisted of at $40 \mathrm{~mm}^{3}$ ( 5 voxels) thresholded at $z=3.3(p<0.001)$, with a peak voxel of $z>3.5$ ( $\left.p<0.0005\right)$. Coordinates are in MNI space and are listed in millimeters.

\section{Volumes}

Of the four a priori volumes, the left nucleus accumbens volume was larger in marijuana users (Figure $1 C$, Table 2), mirroring the increase in gray matter density, although this increase did not meet significance after controlling for multiple comparisons. Alterations in left nucleus accumbens volume were associated, at trend level, with both the number of joints per occasion and smoking occasions per day (Fig. 1C, Table 4), but not with age of onset of marijuana use. To verify that volumetric alterations did not merely reflect group differences in global brain volume, we determined that there were no significant differences in ICV, total brain volume, or gray or white matter volume; there were also no differences in any other deep gray matter regions after controlling for ICV and sex (Table 5).

\section{Topology/shape measures}

Significant shape differences were detected between marijuana users and control participants using both voxelwise and ROI approaches in the right amygdala and left nucleus accumbens (Fig. $2 A, B$, Table 2); these differences remained significant after con- 
Table 4. Linear regression between smoking behavior and structural measures

\begin{tabular}{|c|c|c|c|c|c|c|c|c|}
\hline & Smokin & day & Joints/0 & & Joints/V & & Smoki & \\
\hline & $r^{2}$ & $p$ & $r^{2}$ & $p$ & $r^{2}$ & $p$ & $r^{2}$ & $p$ \\
\hline GMd & & & & & & & & \\
\hline Raccumbens & 0.050 & 0.171 & 0.059 & 0.137 & 0.055 & 0.156 & 0.049 & 0.174 \\
\hline R amygdala & 0.071 & 0.100 & 0.035 & 0.251 & 0.007 & 0.610 & 0.027 & 0.321 \\
\hline Laccumbens & 0.255 & $0.001 *$ & 0.235 & $0.002^{*}$ & 0.141 & 0.020 & 0.115 & 0.035 \\
\hline L amygdala & 0.191 & $0.005^{*}$ & 0.061 & 0.130 & 0.021 & 0.380 & 0.042 & 0.212 \\
\hline Volume & & & & & & & & \\
\hline Raccumbens & 0.015 & 0.450 & 0.097 & 0.051 & 0.027 & 0.307 & 0.003 & 0.714 \\
\hline R amygdala & 0.009 & 0.558 & 0.069 & 0.100 & 0.072 & 0.094 & 0.008 & 0.565 \\
\hline Laccumbens & 0.082 & 0.073 & 0.145 & 0.015 & 0.066 & 0.110 & 0.048 & 0.230 \\
\hline L amygdala & 0.000 & 0.867 & 0.000 & 0.885 & 0.001 & 0.831 & 0.001 & 0.835 \\
\hline Shape & & & & & & & & \\
\hline Raccumbens & 0.231 & $0.002^{*}$ & 0.265 & $0.001^{*}$ & 0.232 & 0.018 & 0.232 & $0.002^{*}$ \\
\hline Ramygdala & 0.296 & $<0.001^{*}$ & 0.414 & $<0.0001 *$ & 0.186 & $0.001^{*}$ & 0.186 & $0.007^{*}$ \\
\hline L accumbens & 0.158 & $0.012^{*}$ & 0.170 & $0.009 *$ & 0.120 & 0.536 & 0.120 & 0.031 \\
\hline L amygdala & 0.004 & 0.685 & 0.006 & 0.643 & 0.016 & 0.439 & 0.002 & 0.785 \\
\hline
\end{tabular}

Values of gray matter density (GMd), volume, and shape were entered into linear regressions with the four measures of marijuana use, yielding the reported $r^{2}$ and $p$-values. $p<0.05$ uncorrected are in bold; an asterisk indicates that these values met correction for multiple comparisons across four regions (e.g., $p<0.0125$ ).

Table 5. Volumes of total brain and subcortical ROls in marijuana users (MJ) and healthy controls (CON)

\begin{tabular}{|c|c|c|c|c|c|c|c|c|c|c|}
\hline & \multicolumn{2}{|l|}{ Controls } & \multicolumn{2}{|l|}{ MJ } & \multicolumn{2}{|c|}{$\begin{array}{l}\text { Variance } \\
\text { accounted } \\
\text { for by ICV }\end{array}$} & \multicolumn{2}{|c|}{$\begin{array}{l}\text { Variance } \\
\text { accounted } \\
\text { for by sex }\end{array}$} & \multicolumn{2}{|c|}{$\begin{array}{l}\text { Variance } \\
\text { accounted } \\
\text { for by group }\end{array}$} \\
\hline & Mean & SD & Mean & SD & $F$ & $p$ & $F$ & $p$ & $F$ & $p$ \\
\hline Total brain & 1228316.23 & 107399.90 & 1207892.96 & 107013.81 & 37.75 & $* * *$ & 5.61 & * & 0.12 & NS \\
\hline Total gray & 652429.33 & 58089.89 & 643401.98 & 58569.35 & 28.87 & $* * *$ & 5.39 & * & 1.03 & NS \\
\hline Total white & 575886.9 & 56070.39 & 564490.98 & 53863.34 & 25.21 & $* * *$ & 2.91 & NS & 0.10 & NS \\
\hline R caudate & 3980.15 & 432.73 & 3936.7 & 393.26 & 3.04 & NS & 2.22 & NS & 0.03 & NS \\
\hline R putamen & 5790.8 & 610.46 & 5811.65 & 605.85 & 1.14 & NS & 3.39 & NS & 0.05 & NS \\
\hline R thalamus & 7737.45 & 1053.86 & 7496.6 & 1065.25 & 12.06 & $* *$ & 0.49 & NS & 0.45 & NS \\
\hline R hippocampus & 4325.05 & 443.61 & 4340.5 & 440.4 & 13.47 & ** & 1.58 & NS & 0.27 & NS \\
\hline L accumbens & 541.35 & 88.87 & 607.95 & 86.24 & 0.28 & NS & 0.01 & NS & 4.66 & * \\
\hline L amygdala & 1698.45 & 323.56 & 1711.35 & 323.03 & 1.19 & NS & 10.76 & $* *$ & 0.09 & NS \\
\hline
\end{tabular}

Total brain is composed of gray matter + white matter + intraventricular CSF. All volumes are reported in cubic millimeters. All structures were entered into a univariate general linear model to examine how ICV, sex, and group (MJ or CON) affected variance of volumes of structures.

${ }^{*} p<0.05 ;{ }^{* *} p<0.01 ;{ }^{* * *} p<0.001$, uncorrected for multiple comparisons.

trolling for age, sex, alcohol use, and cigarette smoking (Table 2). These regions showed significant associations between shape measures and marijuana drug use behaviors (Table 4), but not between shape measures and age of onset of marijuana use.

\section{Multimodal relationships across structural measures}

When we investigated the relationship among gray matter density, volume, and vertices, we found that multimodal relationships in control participants were altered in marijuana users, particularly in the left nucleus accumbens. In control participants, there was a positive relationship (i.e., $r>0.4$ ) between gray matter density and both volume and vertices in the left nucleus accumbens (Fig. 2C, left colorized covariance matrix, Table 6); in the marijuana users, those relationships were largely insignificant (Fig. 2C, right colorized covariance matrix, Table 6). In contrast, for both groups, across all measures, left and right regions were highly correlated (Table 7). Therefore, abnormalities were observed across hemispheres, although they were strongest in the left nucleus accumbens.

\section{Discussion}

The present study demonstrates that, even in young, nondependent marijuana users, morphometric abnormalities relative to nonusers are observable, many of which are exposure dependent. These observations also demonstrate that fundamental relationships observed in covariance analyses among structural measures of controls are absent in marijuana users, suggesting that marijuana use may be associated with a disruption of neural organization in the a priori regions of the nucleus accumbens and amygdala. These findings emphasize the importance of multimodal imaging for two primary reasons. First, convergent evidence across modalities makes a convincing case for a robust finding. In this study, all three structural measures in the left nucleus accumbens were parametrically associated with drug use measures, raising a hypothesis that the etiology of these changes may have been due to drug exposure. Second, multimodal imaging can demonstrate that certain abnormalities may be more detectable using one modality than another due to the different 


\section{A Surface Morphology (Shape): Right Amygdala}
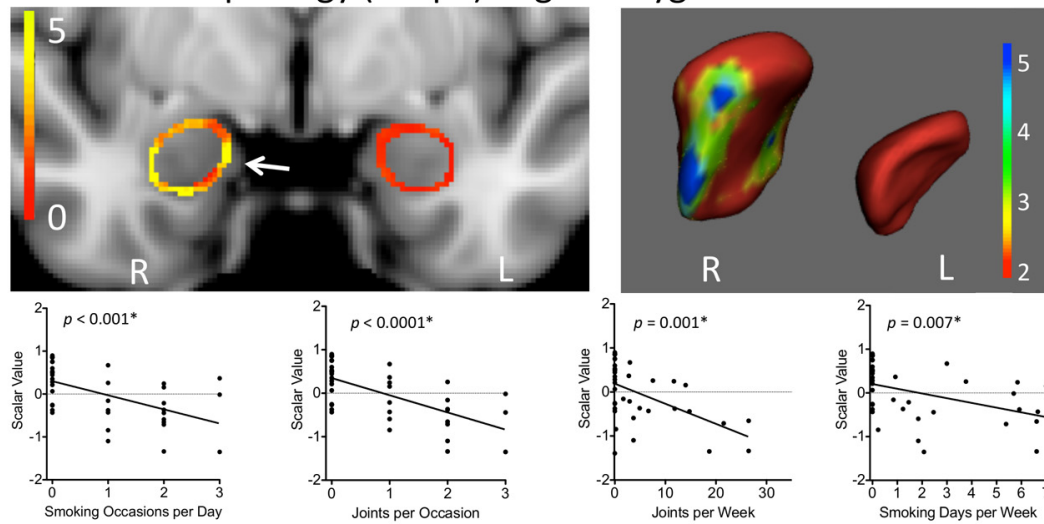

B Surface Morphology (Shape): Nucleus Accumbens
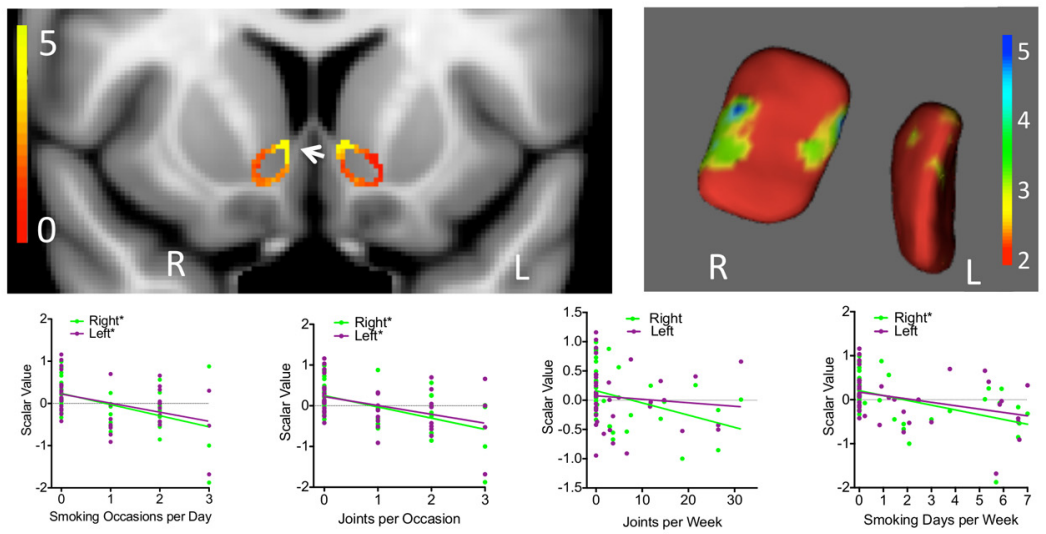

C Correlations Among Structural Measures of the Left Nucleus Accumbens

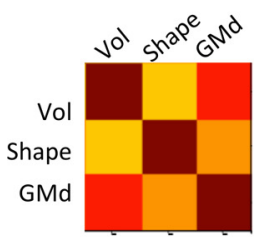

Control Participants

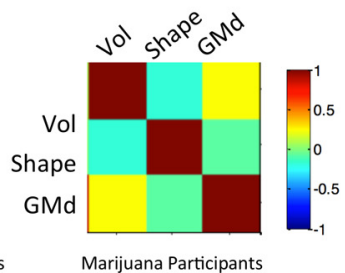

Marijuana Participants
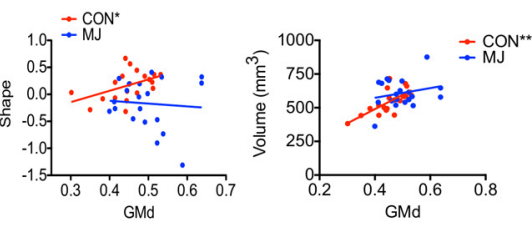

Figure 2. Shape analysis. 2D results of the shape analysis of the amygdala $(\boldsymbol{A})$ and the nucleus accumbens $(\boldsymbol{B})$ show areas that are significantly different between marijuana and control participants (left); 3D results are shown on right. Below each colorized statistical map, differences in shape were significantly associated with several drug use measures. An asterisk after the $p$-value in $\boldsymbol{A}$ and after the left/right color legend in $\boldsymbol{B}$ indicates a significant correlation (corrected). Please see Table 4 for significance after correcting for multiple comparisons. C, Color maps indicate bivariate correlations between modalities in the left nucleus accumbens (left). The relationship between gray matter density and shape and between gray matter density and volume differed between marijuana usersr and control participants; one asterisk indicates a trend correlation; two asterisks indicate a significant correlation (corrected). Please see Table 6 for significance after correcting for multiple comparisons. GMd, Gray matter density; Vol, volume.

etiological sensitivities of different neuroimaging modalities. For example, the amygdala showed salient shape differences in the absence of volumetric differences. Assessing each of these measures alone, along with their relationship together (i.e., covariance), can provide evidence of more robust differences between groups and, potentially, of etiology that can be tested as a hypothesis in subsequent work.

Examining these measures together is important because no one measure is a gold standard; each has caveats associated with it. For example, MRI-based volumetry is approximate for brain structures that have no clear borders between them due to similarity in image intensity values on T1-MRI. Furthermore, global measures of volume lack information on detailed topography
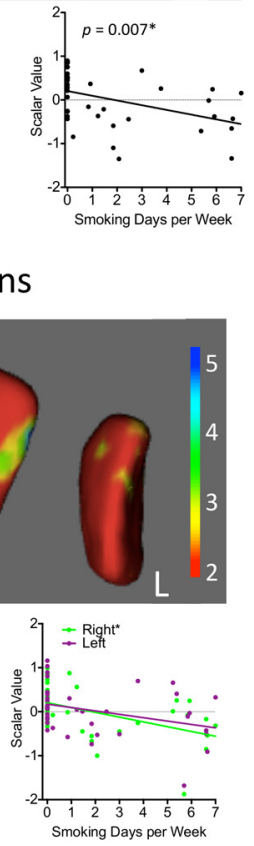

within a given brain structure (Filipek et al., 1989; Filipek et al., 1994; Makris et al., 1999; Fischl et al., 2002). In these cases, information provided by other techniques, such as voxel-based morphometry and shape analyses, may be useful in generating a multifactorial perspective of abnormalities. In voxel-based morphometry analyses, gray matter density is compared across the entire brain at every voxel, allowing the detection of differences in small or large regions, which can be topographically specified with high accuracy (Ashburner and Friston, 2000) even though all brains have been normalized. Finally, shape analyses allow for a comparison of surface geometrical properties of structures between groups (Heimann and Meinzer, 2009) that may not have had an overall volume change or alteration in gray matter density. These multiple aspects of structural information enrich our knowledge related to a structure in terms of size, density, and topography and give us more confidence of the veracity and accuracy of the MRI techniques used and the derived anatomical results.

This study demonstrates that different aspects of brain morphology may be affected by cannabis. In this study, shapeand voxel-based morphometry measures of subcortical regions were consistently affected in an exposure-dependent manner by cannabis, whereas volume was less affected. Since their initial application in addiction and psychiatric research (e.g., Makris et al., 2004), shape analyses are becoming more common in the psychiatric literature, providing useful information about locations and patterns of structural changes. For example, subcortical structural alterations have been reported in thalami of patients with schizophrenia (Harms et al., 2007; Kang et al., 2008; Coscia et al., 2009; Harms et al., 2010), obsessive-compulsive disorders (Kang et al., 2008), Parkinson's disease (McKeown et al., 2008), and Tourette's syndrome (Wang et al., 2007). Subcortical surface alterations may be more sensitive to the effects of cannabis than total volumes. Volume alterations may also be more pronounced with greater duration of use. In our study, the nucleus accumbens and amygdala showed altered surface topology compared with controls, which could potentially lead to volume alterations with continued use.

Both gray matter density and average volume were increased in marijuana participants in the left nucleus accumbens. The density increase was localized to a large area, which clearly represents the extended amygdala as defined by Heimer and Alheid (1991), a neuroanatomical entity implicated in addiction (Koob, 2003). The structures comprising the extended amygdala may be key substrates for the reinforcing actions of drugs and in the negative reinforcing aspect of dependence (Koob, 2003). 
Table 6. Bivariate correlations between modalities in marijuana users (MJ) and healthy controls (CON)

\begin{tabular}{|c|c|c|c|c|c|c|}
\hline \multirow{3}{*}{ 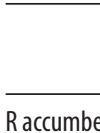 } & \multicolumn{3}{|l|}{$\mathrm{CON}$} & \multicolumn{3}{|l|}{ MJ } \\
\hline & Volume & Shape & GMd & Volume & Shape & GMd \\
\hline & \multicolumn{6}{|c|}{$\begin{array}{c}\text { Raccumbens } \\
\text { Volume }\end{array}$} \\
\hline$r$ & 1 & 0.486 & 0.429 & 1 & 0.116 & 0.532 \\
\hline$p$ & 0 & $0.030^{*}$ & 0.059 & 0 & 0.628 & $0.017^{*}$ \\
\hline \multicolumn{7}{|c|}{ Shape } \\
\hline$r$ & 0.486 & 1 & 0.353 & 0.116 & 1 & -0.011 \\
\hline$p$ & $0.030 *$ & 0 & 0.126 & 0.628 & 0 & -0.33 \\
\hline \multicolumn{7}{|l|}{ GMd } \\
\hline$r$ & 0.429 & 0.353 & 1 & 0.532 & -0.011 & 1 \\
\hline$p$ & 0.059 & 0.126 & 0 & $0.017^{*}$ & 0.964 & 0 \\
\hline \multicolumn{7}{|c|}{ R amygdala } \\
\hline \multicolumn{7}{|c|}{ Volume } \\
\hline$r$ & 1 & 0.169 & -0.244 & 1 & 0.253 & 0.115 \\
\hline$p$ & 0 & 0.476 & 0.299 & 0 & 0.282 & 0.630 \\
\hline \multicolumn{7}{|l|}{ Shape } \\
\hline$r$ & 0.169 & 1 & -0.037 & 0.253 & 1 & 0.445 \\
\hline$p$ & 0.476 & 0 & 0.876 & 0.282 & 0 & $0.049 *$ \\
\hline \multicolumn{7}{|l|}{ GMd } \\
\hline$r$ & -0.244 & -0.037 & 1 & 0.115 & 0.445 & 1 \\
\hline$p$ & 0.299 & 0.876 & 0 & 0.630 & $0.049^{*}$ & 0 \\
\hline \multicolumn{7}{|c|}{ Laccumbens } \\
\hline \multicolumn{7}{|c|}{ Volume } \\
\hline$r$ & 1 & 0.358 & 0.688 & 1 & -0.173 & 0.235 \\
\hline$p$ & 0 & 0.121 & $0.001^{* *}$ & 0 & 0.466 & 0.320 \\
\hline \multicolumn{7}{|l|}{ Shape } \\
\hline$r$ & 0.358 & 1 & 0.459 & -0.173 & 1 & -0.077 \\
\hline$p$ & 0.121 & 0 & $0.042 *$ & 0.466 & 0 & 0.748 \\
\hline \multicolumn{7}{|l|}{ GMd } \\
\hline$r$ & 0.688 & 0.459 & 1 & 0.235 & -0.077 & 1 \\
\hline$p$ & $0.001^{* *}$ & $0.042^{*}$ & 0 & 0.320 & 0.748 & 0 \\
\hline \multicolumn{7}{|c|}{ Lamygdala } \\
\hline \multicolumn{7}{|c|}{ Volume } \\
\hline$r$ & 1 & 0.731 & 0.085 & 1 & 0.134 & 0.021 \\
\hline$p$ & 0 & $<0.001^{* *}$ & 0.722 & 0 & 0.573 & 0.929 \\
\hline \multicolumn{7}{|c|}{ Shape } \\
\hline$r$ & 0.731 & 1 & 0.06 & 0.134 & 1 & -0.179 \\
\hline \multirow{2}{*}{\multicolumn{7}{|c|}{ GMd }} \\
\hline & & & & & & \\
\hline$r$ & 0.085 & 0.06 & 1 & 0.021 & -0.179 & 1 \\
\hline$p$ & 0.722 & 0.801 & 0 & 0.929 & 0.449 & 0 \\
\hline
\end{tabular}

$p<0.05$ uncorrected are bolded. Please note, after correcting for multiple comparisons $(p<0.002)$, that only the left accumbens correlation between volume and gray matter density (GMd) and the left amygdala correlations between volume and shape were significant in controls.

${ }^{*} p<0.05 ;{ }^{* *} p<0.01$.

Table 7. Bivariate correlations within modalities in the right and left hemispheres in marijuana users (MJ) and healthy controls (CON)

\begin{tabular}{|c|c|c|c|c|}
\hline & \multicolumn{2}{|l|}{$\mathrm{CON}$} & \multicolumn{2}{|l|}{ MJ } \\
\hline & $r$ & $p$ & $r$ & $p$ \\
\hline \multicolumn{5}{|l|}{ Accumbens } \\
\hline Volume & 0.659 & $0.002^{* *}$ & 0.532 & $0.016^{*}$ \\
\hline Shape & 0.581 & $0.007^{* *}$ & 0.674 & $0.001^{* *}$ \\
\hline GMd & 0.623 & $0.003 * *$ & 0.878 & $<0.0001^{* *}$ \\
\hline \multicolumn{5}{|l|}{ Amygdala } \\
\hline Volume & 0.791 & $<0.0001^{* *}$ & 0.700 & $0.001 * *$ \\
\hline Shape & 0.531 & $0.016^{*}$ & 0.466 & $0.039 *$ \\
\hline GMd & 0.690 & $0.001 * *$ & 0.509 & $0.022 *$ \\
\hline
\end{tabular}

Increased gray matter density in this region is consistent with findings in animal studies of drug use. Researchers have reported a $6.9 \%$ increase in the number of dendritic branches and increased density of dendritic spines in the shell of the nucleus accumbens in amphetamine- and cocaine-treated rats (Robinson and Kolb, 1999) and this increase appears to persist long after acute administration. These results have been replicated using nicotine (Gonzalez et al., 2005) and cannabis (Kolb et al., 2006). In a study in which rats were given doses of THC that were within the range that might be experienced by human marijuana users, prior exposure to THC increased the length of the dendrites and the number of dendritic branches in the shell of the nucleus accumbens (in contrast to an absence of effects in the hippocampus, striatum, orbital frontal cortex, parietal cortex, or occipital cortex; Kolb et al., 2006). Dendritic arborization changes may relate to an increase in dopamine, because acute administration of drugs of abuse (e.g., THC; Chen et al., 1990) produces increases in extracellular levels of dopamine (DA) in the nucleus accumbens (Pontieri et al., 1995).

Interestingly, the left nucleus accumbens was consistently affected by cannabis use across all three modalities. This structure also showed differences between marijuana and control participants in the multimodal relationship between gray matter density and both shape and volume. Few other associations of measures across modalities differed between marijuana and control participants. It will be important for follow-up work to assess the emergence of further abnormalities with prolonged marijuana use.

The present study did not find any differences in amygdala volumes between marijuana users and control participants, but did find that surfaces of the right amygdala were deformed inwards and this diminishment was highly correlated with drug use behavior. These exposure-dependent deformations may precede more pronounced volumetric changes, because others have reported a reduction in amygdala volumes in long-term, heavy users (Yücel et al., 2008; Schacht et al., 2012). Such an observation is also consistent with data showing a negative correlation between level of cannabis dependence and amygdala gray matter density (Cousijn et al., 2012). Our observations indicate that such changes may occur before dependence, which is intriguing in the context that the amygdala appears to play an important role in drug craving (Breiter et al., 1997; Childress et al., 1999; Bonson et al., 2002).

In addition to the a priori regions of the nucleus accumbens and amygdala, the whole-brain gray matter density analysis revealed other brain regions that showed reduced density in marijuana users compared with control participants, including several regions in the prefrontal cortex: right/left frontal pole, right dorsolateral prefrontal cortex, and right middle frontal gyrus (although another small region in the right middle frontal gyrus showed higher gray matter density in marijuana users). Countless studies have shown that prefrontal cortex dysfunction is involved with decision-making abnormalities in addiction (e.g., Bechara, 2001), and functional MRI and magnetic resonance spectroscopy studies have shown that cannabis use may affect the function of this region (Quickfall and Crockford, 2006; Hermann et al., 2007). Furthermore, diffusion tensor imaging studies have shown that cannabis use may affect the integrity of white matter fiber tracts in prefrontal regions (Gruber and Yurgelun-Todd, 2005). A study examining the structural effects of cannabis on the prefrontal cortex reported greater gray matter density in the precentral gyrus of marijuana users (Matochik et al., 2005). More studies are needed with larger cohorts to fully examine the effect of cannabis use on prefrontal structures.

This preliminary study has several caveats. First, the sample size does not provide power to examine complex interactions such as sex differences. Because this is a cross-sectional study, causation cannot be determined, although marijuana exposure 
parametrically correlated with structural differences, which suggests the possibility of causation. Longitudinal studies are needed to determine whether marijuana exposure explicitly leads to the differences observed in this study. Furthermore, this study did not include quantifiable marijuana metabolite levels, which would have provided further information about the amount of marijuana exposure. This measure could be incorporated into future studies as a complementary measure to detailed timeline follow-back measures of drug use. Finally, age of onset was collected for marijuana use only. Early exposure to alcohol may have also affected brain structure (although no participant met criteria for past alcohol abuse or dependence).

The results of this study indicate that in young, recreational marijuana users, structural abnormalities in gray matter density, volume, and shape of the nucleus accumbens and amygdala can be observed. Pending confirmation in other cohorts of marijuana users, the present findings suggest that further study of marijuana effects are needed to help inform discussion about the legalization of marijuana. These results extend prior studies showing that drugs of abuse that are known to elevate DA release are associated with structural abnormalities in the brain and related disruptions in behavior (Makris et al., 2004; Makris et al., 2008). The multimodal convergence of these findings also points to the salience of structural differences in the brain related to drug exposure and strongly argues that human addiction research, if not all psychiatric study, must move past a predominant focus on neurotransmission.

\section{References}

Office of Applied Studies, Substance Abuse and Mental Health Services Administration. Office of Applied Studies, US Department of Health and Human Services 2008 National survey on drug use and health, 2008 (ICPSR 26701). Washington, DC: US Department of Health and Human Services.

Andersson JLR, Jenkinson M, Smith S (2007) Non-linear registration, aka Spatial normalisation. In: FMRIB technical report TR07JA2. Available from: http://www.fmrib.ox.ac.uk/analysis/techrep.

Ashburner J, Friston KJ (2000) Voxel-based morphometry-the methods. Neuroimage 11:805-821. CrossRef Medline

Azad SC, Monory K, Marsicano G, Cravatt BF, Lutz B, Zieglgänsberger W, Rammes G (2004) Circuitry for associative plasticity in the amygdala involves endocannabinoid signaling. J Neurosci 24:9953-9961. CrossRef Medline

Bechara A (2001) Neurobiology of decision-making: risk and reward. Semin Clin Neuropsychiatry 6:205-216. CrossRef Medline

Blood AJ, Zatorre RJ (2001) Intensely pleasurable responses to music correlate with activity in brain regions implicated in reward and emotion. Proc Natl Acad Sci U S A 98:11818-11823. CrossRef Medline

Blood AJ, Iosifescu DV, Makris N, Perlis RH, Kennedy DN, Dougherty DD, Kim BW, Lee MJ, Wu S, Lee S, Calhoun J, Hodge SM, Fava M, Rosen BR, Smoller JW, Gasic GP, Breiter HC; Phenotype Genotype Project on Addiction and Mood Disorders (2010) Microstructural abnormalities in subcortical reward circuitry of subjects with major depressive disorder. PLoS One 5:e13945. CrossRef Medline

Blood AJ, Kuster JK, Woodman SC, Kirlic N, Makhlouf ML, Multhaupt-Buell TJ, Makris N, Parent M, Sudarsky LR, Sjalander G, Breiter H, Breiter HC, Sharma N (2012) Evidence for altered basal ganglia-brainstem connections in cervical dystonia. PLoS One 7:e31654. CrossRef Medline

Bonson KR, Grant SJ, Contoreggi CS, Links JM, Metcalfe J, Weyl HL, Kurian V, Ernst M, London ED (2002) Neural systems and cue-induced cocaine craving. Neuropsychopharmacology 26:376-386. CrossRef Medline

Breiter HC, Gollub RL, Weisskoff RM, Kennedy DN, Makris N, Berke JD, Goodman JM, Kantor HL, Gastfriend DR, Riorden JP, Mathew RT, Rosen BR, Hyman SE (1997) Acute effects of cocaine on human brain activity and emotion. Neuron 19:591-611. CrossRef Medline

Breiter HC, Aharon I, Kahneman D, Dale A, Shizgal P (2001) Functional imaging of neural responses to expectancy and experience of monetary gains and losses. Neuron 30:619-639. CrossRef Medline
Burns HD, Van Laere K, Sanabria-Bohórquez S, Hamill TG, Bormans G, Eng WS, Gibson R, Ryan C, Connolly B, Patel S, Krause S, Vanko A, Van Hecken A, Dupont P, De Lepeleire I, Rothenberg P, Stoch SA, Cote J, Hagmann WK, Jewell JP, et al. (2007) [18F]MK-9470, a positron emission tomography (PET) tracer for in vivo human PET brain imaging of the cannabinoid-1 receptor. Proc Natl Acad Sci U S A 104:9800-9805. CrossRef Medline

Chen JP, Paredes W, Li J, Smith D, Lowinson J, Gardner EL (1990) Delta 9-tetrahydrocannabinol produces naloxone-blockable enhancement of presynaptic basal dopamine efflux in nucleus accumbens of conscious, freely-moving rats as measured by intracerebral microdialysis. Psychopharmacology (Berl) 102:156-162. CrossRef Medline

Childress AR, Mozley PD, McElgin W, Fitzgerald J, Reivich M, O'Brien CP (1999) Limbic activation during cue-induced cocaine craving. Am J Psychiatry 156:11-18. Medline

Coscia DM, Narr KL, Robinson DG, Hamilton LS, Sevy S, Burdick KE, Gunduz-Bruce H, McCormack J, Bilder RM, Szeszko PR (2009) Volumetric and shape analysis of the thalamus in first-episode schizophrenia. Hum Brain Mapp 30:1236-1245. CrossRef Medline

Cousijn J, Wiers RW, Ridderinkhof KR, van den Brink W, Veltman DJ, Goudriaan $\mathrm{AE}$ (2012) Grey matter alterations associated with cannabis use: results of a VBM study in heavy cannabis users and healthy controls. Neuroimage 59:3845-3851. CrossRef Medline

Downer E, Boland B, Fogarty M, Campbell V (2001) Delta 9-tetrahydrocannabinol induces the apoptotic pathway in cultured cortical neurones via activation of the CB1 receptor. Neuroreport 12:3973-3978. CrossRef Medline

Filipek PA, Kennedy DN, Caviness VS Jr, Rossnick SL, Spraggins TA, Starewicz PM (1989) Magnetic resonance imaging-based brain morphometry: development and application to normal subjects. Ann Neurol 25:61-67. Medline

Filipek PA, Richelme C, Kennedy DN, Caviness VS Jr (1994) The young adult human brain: an MRI-based morphometric analysis. Cereb Cortex 4:344-360. CrossRef Medline

First MB, Spitzer, Robert L, Gibbon Miriam, and Williams, Janet B.W (2002) Structured clinical interview for DSM-IV-TR axis I disorders, research version, patient edition (SCID-I/P). New York: Biometrics Research, New York State Psychiatric Institute.

Fischl B, Salat DH, Busa E, Albert M, Dieterich M, Haselgrove C, van der Kouwe A, Killiany R, Kennedy D, Klaveness S, Montillo A, Makris N, Rosen B, Dale AM (2002) Whole brain segmentation: automated labeling of neuroanatomical structures in the human brain. Neuron 33:341355. CrossRef Medline

Fraser AD, Coffin L, Worth D (2002) Drug and chemical metabolites in clinical toxicology investigations: the importance of ethylene glycol, methanol and cannabinoid metabolite analyses. Clin Biochem 35:501511. CrossRef Medline

Gálvez-Buccollini JA, Paz-Soldan V, Herrera P, DeLea S, Gilman RH, Anthony JC (2008) Links between sex-related expectations about alcohol, heavy episodic drinking and sexual risk among young men in a shantytown in Lima, Peru. Int Fam Plan Perspect 34:15-20. CrossRef Medline

Gasic GP, Smoller JW, Perlis RH, Sun M, Lee S, Kim BW, Lee MJ, Holt DJ, Blood AJ, Makris N, Kennedy DK, Hoge RD, Calhoun J, Fava M, Gusella JF, Breiter HC (2009) BDNF, relative preference, and reward circuitry responses to emotional communication. Am J Med Genet B Neuropsychiatr Genet 150B:762-781. CrossRef Medline

Gilman JM, Ramchandani VA, Davis M, Bjork JW, Hommer DW (2008) Why we like to drink: a functional magnetic resonance imaging study of the rewarding and anxiolytic effects of alcohol. J Neurosci 28:4583-4591. CrossRef Medline

Gonzalez CL, Gharbawie OA, Whishaw IQ, Kolb B (2005) Nicotine stimulates dendritic arborization in motor cortex and improves concurrent motor skill but impairs subsequent motor learning. Synapse 55:183-191. CrossRef Medline

Gosling SD, Rentfrow PJ, Swann WB Jr (2003) A very brief measure of the big five personality domains. Journal of Research in Personality 37:504528. CrossRef

Gruber SA, Yurgelun-Todd DA (2005) Neuroimaging of marijuana smokers during inhibitory processing: a pilot investigation. Brain Res Cogn Brain Res 23:107-118. CrossRef Medline

Hamilton M (1960) A rating scale for depression. J Neurol Neurosurg Psychiatry 23:56-62. CrossRef Medline

Harms MP, Wang L, Mamah D, Barch DM, Thompson PA, Csernansky JG 
(2007) Thalamic shape abnormalities in individuals with schizophrenia and their nonpsychotic siblings. J Neurosci 27:13835-13842. CrossRef Medline

Harms MP, Wang L, Campanella C, Aldridge K, Moffitt AJ, Kuelper J, Ratnanather JT, Miller MI, Barch DM, Csernansky JG (2010) Structural abnormalities in gyri of the prefrontal cortex in individuals with schizophrenia and their unaffected siblings. Br J Psychiatry 196:150-157. CrossRef Medline

Heimann T, Meinzer HP (2009) Statistical shape models for 3D medical image segmentation: a review. Med Image Anal 13:543-563. CrossRef Medline

Heimer L, Alheid GF (1991) Piecing together the puzzle of basal forebrain anatomy. Adv Exp Med Biol 295:1-42. CrossRef Medline

Henry JA, Oldfield WL, Kon OM (2003) Comparing cannabis with tobacco. BMJ 326:942-943. CrossRef Medline

Hermann D, Sartorius A, Welzel H, Walter S, Skopp G, Ende G, Mann K (2007) Dorsolateral prefrontal cortex N-acetylaspartate/total creatine (NAA/tCr) loss in male recreational cannabis users. Biol Psychiatry 61: 1281-1289. CrossRef Medline

Kang DH, Kim SH, Kim CW, Choi JS, Jang JH, Jung MH, Lee JM, Kim SI, Kwon JS (2008) Thalamus surface shape deformity in obsessivecompulsive disorder and schizophrenia. Neuroreport 19:609-613. CrossRef Medline

Karschner EL, Darwin WD, McMahon RP, Liu F, Wright S, Goodwin RS, Huestis MA (2011) Subjective and physiological effects after controlled Sativex and oral THC administration. Clin Pharmacol Ther 89:400-407. CrossRef Medline

Kolb B, Gorny G, Limebeer CL, Parker LA (2006) Chronic treatment with Delta-9-tetrahydrocannabinol alters the structure of neurons in the nucleus accumbens shell and medial prefrontal cortex of rats. Synapse 60: 429-436. CrossRef Medline

Koob GF (2003) Neuroadaptive mechanisms of addiction: studies on the extended amygdala. Eur Neuropsychopharmacol 13:442-452. CrossRef Medline

Koob GF, Volkow ND (2010) Neurocircuitry of addiction. Neuropsychopharmacology 35:217-238. CrossRef Medline

Lawston J, Borella A, Robinson JK, Whitaker-Azmitia PM (2000) Changes in hippocampal morphology following chronic treatment with the synthetic cannabinoid WIN 55,212-2. Brain Res 877:407-410. CrossRef Medline

Lorenzetti V, Lubman DI, Whittle S, Solowij N, Yücel M (2010) Structural MRI findings in long-term cannabis users: what do we know? Subst Use Misuse 45:1787-1808. CrossRef Medline

Lupica CR, Riegel AC, Hoffman AF (2004) Marijuana and cannabinoid regulation of brain reward circuits. Br J Pharmacol 143:227-234. CrossRef Medline

Makris N, Meyer JW, Bates JF, Yeterian EH, Kennedy DN, Caviness VS (1999) MRI-Based topographic parcellation of human cerebral white matter and nuclei. II. Rationale and applications with systematics of cerebral connectivity. Neuroimage 9:18-45. CrossRef Medline

Makris N, Gasic GP, Seidman LJ, Goldstein JM, Gastfriend DR, Elman I, Albaugh MD, Hodge SM, Ziegler DA, Sheahan FS, Caviness VS Jr, Tsuang MT, Kennedy DN, Hyman SE, Rosen BR, Breiter HC (2004) Decreased absolute amygdala volume in cocaine addicts. Neuron 44:729-740. CrossRef Medline
Makris N, Gasic GP, Kennedy DN, Hodge SM, Kaiser JR, Lee MJ, Kim BW, Blood AJ, Evins AE, Seidman LJ, Iosifescu DV, Lee S, Baxter C, Perlis RH, Smoller JW, Fava M, Breiter HC (2008) Cortical thickness abnormalities in cocaine addiction-a reflection of both drug use and a pre-existing disposition to drug abuse? Neuron 60:174-188. CrossRef Medline

Matochik JA, Eldreth DA, Cadet JL, Bolla KI (2005) Altered brain tissue composition in heavy marijuana users. Drug Alcohol Depend 77:23-30. CrossRef Medline

McKeown MJ, Uthama A, Abugharbieh R, Palmer S, Lewis M, Huang X (2008) Shape (but not volume) changes in the thalami in Parkinson disease. BMC Neurol 8:8. CrossRef Medline

Mohler-Kuo M, Lee JE, Wechsler H (2003) Trends in marijuana and other illicit drug use among college students: results from 4 Harvard School of Public Health College Alcohol Study surveys: 1993-2001. J Am Coll Health 52:17-24. CrossRef Medline

Nichols TE, Holmes AP (2002) Nonparametric permutation tests for functional neuroimaging: a primer with examples. Hum Brain Mapp 15:1-25. CrossRef Medline

Pontieri FE, Tanda G, Di Chiara G (1995) Intravenous cocaine, morphine, and amphetamine preferentially increase extracellular dopamine in the "shell" as compared with the "core" of the rat nucleus accumbens. Proc Natl Acad Sci U S A 92:12304-12308. CrossRef Medline

Quickfall J, Crockford D (2006) Brain neuroimaging in cannabis use: a review. J Neuropsychiatry Clin Neurosci 18:318-332. CrossRef Medline

Robinson TE, Kolb B (1999) Alterations in the morphology of dendrites and dendritic spines in the nucleus accumbens and prefrontal cortex following repeated treatment with amphetamine or cocaine. Eur J Neurosci 11:1598-1604. CrossRef Medline

Saunders JB, Aasland OG, Babor TF, de la Fuente JR, Grant M (1993) Development of the Alcohol Use Disorders Identification Test (AUDIT): WHO collaborative project on early detection of persons with harmful alcohol consumption-II. Addiction 88:791-804. CrossRef Medline

Schacht JP, Hutchison KE, Filbey FM (2012) Associations between cannabinoid receptor-1 (CNR1) variation and hippocampus and amygdala volumes in heavy cannabis users. Neuropsychopharmacology 37:2368-2376. CrossRef Medline

Sobell MB, Sobell LC, Klajner F, Pavan D, Basian E (1986) The reliability of a timeline method for assessing normal drinker college students' recent drinking history: utility for alcohol research. Addict Behav 11:149-161. CrossRef Medline

Spielberger CD, Gorssuch, RL., Lushene, PR., Vagg, PR., and Jacobs, GA (1983) Manual for the State-Trait Anxiety Inventory. Palo Alto, CA: Consulting Psychologists.

van der Kouwe AJ, Benner T, Fischl B, Schmitt F, Salat DH, Harder M, Sorensen AG, Dale AM (2005) On-line automatic slice positioning for brain MR imaging. Neuroimage 27:222-230. CrossRef Medline

van der Kouwe AJ, Benner T, Salat DH, Fischl B (2008) Brain morphometry with multiecho MPRAGE. Neuroimage 40:559-569. CrossRef Medline

Wang L, Lee DY, Bailey E, Hartlein JM, Gado MH, Miller MI, Black KJ (2007) Validity of large-deformation high dimensional brain mapping of the basal ganglia in adults with Tourette syndrome. Psychiatry Res 154: 181-190. CrossRef Medline

Yücel M, Solowij N, Respondek C, Whittle S, Fornito A, Pantelis C, Lubman DI (2008) Regional brain abnormalities associated with long-term heavy cannabis use. Arch Gen Psychiatry 65:694-701. CrossRef Medline 